\title{
บusisersaly
}

\section{Novel core-shell fiber delivery system for synergistic treatment of cervical cancer}

Shen, S. F., Zhu, L. F., Liu, J., Ali, A., Zaman, A., Ahmad, Z., Chen, X., \& Chang, M. W. (2020). Novel core-shell fiber delivery system for synergistic treatment of cervical cancer. Journal of Drug Delivery Science and Technology, 59, [101865]. https://doi.org/10.1016/j.jddst.2020.101865

Link to publication record in Ulster University Research Portal

\section{Published in:}

Journal of Drug Delivery Science and Technology

\section{Publication Status:}

Published (in print/issue): 31/10/2020

DOI:

10.1016/j.jddst.2020.101865

\section{Document Version}

Author Accepted version

\section{General rights}

Copyright for the publications made accessible via Ulster University's Research Portal is retained by the author(s) and / or other copyright owners and it is a condition of accessing these publications that users recognise and abide by the legal requirements associated with these rights.

\section{Take down policy}

The Research Portal is Ulster University's institutional repository that provides access to Ulster's research outputs. Every effort has been made to ensure that content in the Research Portal does not infringe any person's rights, or applicable UK laws. If you discover content in the Research Portal that you believe breaches copyright or violates any law, please contact pure-support@ulster.ac.uk. 


\section{Ulster}

\section{University}

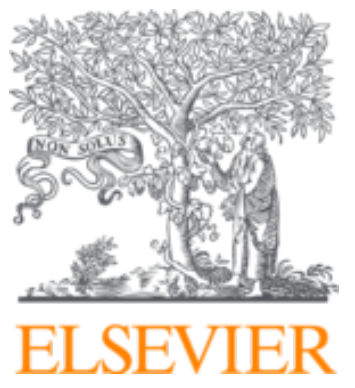

(C) 2020. This manuscript version is made available under the CCBY-NC-ND 4.0 license http://creativecommons.org/licenses/by-nc$\mathrm{nd} / 4.0 /$ 


\section{Novel core-shell fiber delivery system for synergistic treatment of cervical cancer}

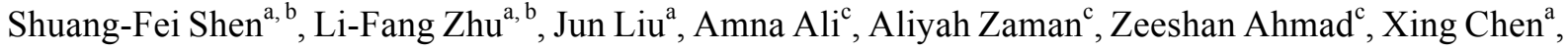
Ming-Wei Chang ${ }^{\mathrm{a}, \mathrm{b}, \mathrm{d}^{*}}$

a Key Laboratory for Biomedical Engineering of Education Ministry of China, Zhejiang University, Hangzhou, 310027, P. R. China.

b Zhejiang Provincial Key Laboratory of Cardio-Cerebral Vascular Detection Technology and Medicinal Effectiveness Appraisal, College of Biomedical Engineering \& Instrument Science, Zhejiang University, Hangzhou, 310027, P. R. China.

c Leicester School of Pharmacy, De Montfort University, The Gateway, Leicester, LE1 9BH, UK.

d Nanotechnology and Integrated Bioengineering Centre, University of Ulster, Jordanstown Campus, Newtownabbey, BT37 0QB, Northern Ireland, UK.

\section{Corresponding author}

Dr. Ming-Wei Chang

*Email: m.chang@ulster.ac.uk; Tel: + 442895367142 


\begin{abstract}
Ganoderma lucidum triterpenoids (GLT) possess advantageous characteristics including antiinflammatory, anti-oxidant and anti-cancer properties. In this study, a drug loaded core-shell fibrous system was engineered using the coaxial electrospinning method. The core comprised polycaprolactone and GTL whilst the shell contained polyethylene oxide with anti-cancer drug methotrexate. The morphology and structure, chemical composition, biocompatibility and in vitro release profile of the encapsulated GLT was assessed. Scanning electron microscopy images showed cylindrical fibers were developed whilst fluorescence microscopy confirmed the successful formation of core-shell fibers. Increasing GLT concentration from $2 \mathrm{wt} \%$ to $6 \mathrm{wt} \%$ resulted in an increase in mean fiber diameter from $2.29 \pm 1.26 \mu \mathrm{m}$ to $4.65 \pm 2.30 \mu \mathrm{m}$, respectively. Fourier transform infrared spectroscopy, X-ray diffraction and differential scanning calorimetry analysis all confirmed that both drugs were encapsulated in amorphous form while contact angle hysteresis showed engineered fibres to possess good hydrophilicity. In vitro drug release tests indicated the release of methotrexate $\left(R^{2}=0.9941\right)$ and GLT $\left(\mathrm{R}^{2}=0.9924\right)$ were controlled by Fick Diffusion. In vitro cell culture experiments proved that the combined use of traditional Chinese medicine and current western medicine has good application prospects in the treatment of cervical cancer.
\end{abstract}

Keywords: Methotrexate; Ganoderma lucidum triterpenoids; coaxial electrospinning; core-shell fibers. 


\section{Introduction}

Ganoderma lucidum is a polypore fungus part of the Ganodermataceae family. It has been used for many years as a functional food and a medicine to promote health and longevity in the Asian community[1]. Ganoderma lucidum triterpenoids (GLT) are thought to be the reason as to why this fungus has a long history of effectiveness. GLT are the main component of Ganoderma lucidum spore powder (GLSP); the spores of G. lucidum[2]. GLT have shown a wide range of advantageous properties and have shown positive effects in anti-cancer therapy[3], anti-inflammation[4], anti-oxidation[5] and anti-proliferation[6]. The study results indicated that there was no obvious detectable toxicity for the GLT, even at a high dosage $5000 \mathrm{mg}$ of GLT in mice per kg [7]. Despite these valuable applications, the use of these compounds is limited as they can be easily oxidised and the process of industrial extraction can prove difficult. As a result, it is necessary to explore the composition and biological activity of triterpenoids present in GLSP which may optimize and develop triterpenoid-based products.

Electrospinning is a branch of electrohydrodynamic atomisation (EHDA) which enables the controlled engineering of single or multi-layered fibers on the micro and nanoscale. The fundamental principles of this technology involve introducing a voltage to a highly viscous formulation which is being fed through a conductive processing needle. Due to the presence of various forces acting on the solution (i.e. surface tension, gravity, electrostatic repulsion), the formulation exits the processing needle in the form of a "Taylor Cone" and due to high viscosity values, the solution is stretched from the needle exit[8]. This stretching of the solution enables the highly volatile solvent used to prepare the solution to evaporate; resulting in three-dimensional polymeric fibers. These structures have gained extensive attention in a multitude of applications ranging from tissue regeneration, diagnostics and pharmaceutical drug delivery[9-11].

Various developments to this basic set-up have been successful in recent years; the most common being coaxial electrospinning. Here, multi-layered fibers can be engineered by feeding two separate immiscible polymeric solutions through coaxially arranged conductive processing needles; resulting in core-shell fibers. The obtained fibers have excellent properties including high porosity and large surface area to volume ratio[12]. A range of materials can be utilized with this technology. Organic materials (including polymers) are dissolved in appropriate solvents to form homogeneous solutions without degradation [13]. The most critical advantage of these core-shell fibers is ability to load multiple drugs into the core and shell layers in a single-step process. Dual drug delivery is a sought-after application is easily achievable with coaxial electrospinning whilst also yielding fibers capable of possessing adequate morphology, hydrophobicity and mechanical properties[14].

The main function of the polymer in the formation of coaxially developed fibers is to act as a carrier and to provide controlled release of the encapsulated drugs. The polymer can also be used to protect vulnerable or toxic ingredients. Polycaprolactone (PCL) is synthetic, biodegradable aliphatic 
polyester[15] which has been proven to be biocompatible and is easily modified to develop structure of various morphologies[16, 17]. PCL has been broadly studied as a biopolymer and has found to be of extensive use in drug delivery systems, tissue engineering[16] and in particular wound dressings[15]. Polyethylene oxide (PEO) is also a biodegradable polymer with good biocompatibility. It is most commonly used as a matrix in drug delivery[18]. It is common knowledge that by amalgamating hydrophilic and hydrophobic polymers, the resulting polymeric mixture can possess improved mechanical strength and thermal stability[19]. Hence, here PCL (hydrophobic) and PEO (water-soluble) were used in combination.

Methotrexate (2,4-diamino- $\mathrm{N}_{10}$-methylpropylglutamic acid, MTX) is a folic acid antimetabolite which has found to be useful in the treatment of solid tumor, haematological malignancies and autoimmune diseases[20]. In current cancer therapeutics, MTX plays an important role in the treatment of breast cancer, lung cancer, non-Hodgkin's lymphoma, osteosarcoma and cervical cancer[21]. The latter is the second most common malignancy in women globally[22] hence it is critical to develop synergistic strategies in cancer treatment using surgery, chemotherapy and radiation therapy.

As highlighted earlier, despite the prominent effects and reduced side effects of GLT products in preventative care and therapeutics, the content of GLT in GLSP is very limited and its extraction can also prove to be difficult due to elevated process parameters (i.e. temperature). GLT extraction is also a time-consuming process[23]. The oxidation of GLT in air also limits the practical application of the active. Therefore, it is necessary to protect the extracted component during processing and delivery. By developing an efficient coating method for GLT, the application potential of the active substance will be greatly improved. In the present study, coaxial electrospinning was utilised to develop core-shell dual drug loaded fibers. The coaxial electrospun fiber membrane (CESFM) was loaded with MTX and GLT. PEO formed the shell and PCL formed the core layer. This core-shell structure was used to control the drug release and maximise GLT potential. In addition, properties of the fabricated fibers such as morphology, physical and mechanical properties were characterised. Furthermore, the drug coating effect and release kinetics of the two drugs were explored and evaluated. Finally, the inhibitory effect of the CESFM on cervical cancer cells were examined.

\section{Materials and Methods}

\subsection{Materials}

GLSP was obtained from Tianhe Agriculture Group (Zhejiang, China). The product met the requirements of GB7069 and was preserved at $-4{ }^{\circ} \mathrm{C}$ in complete darkness until any experimentation. Polycaprolactone (PCL) $\left(\mathrm{Mw}=8 \times 10^{4} \mathrm{~g} / \mathrm{mol}\right)$ was purchased from Sigma-Aldrich, St Louis, USA. Polyethylene oxide $(\mathrm{PEO})\left(\mathrm{Mw}=9.0 \times 10^{5} \mathrm{~g} / \mathrm{mol}\right)$ was obtained from Huagao Fine Chemical Co., Ltd. China. Methotrexate (MTX) was purchased from Nanjing Dulai Biotechnology Co., Ltd. (Nanjing, 
China). Glacial acetic acid, absolute ethyl alcohol and phosphate buffer saline (PBS, $\mathrm{pH}=7.4$ ) were supplied by Sinopharm Chemical Reagent (China). Dulbecco's modified eagle medium (DMEM) was supplied by Gibco, Carlsbad, California, USA. Fetal bovine serum (FBS) was obtained from Sijiqin, Hangzhou, China. Deionized water (DI) was obtained from ultrapure water purifier (Millipore Milli-Q, Bedford, USA). GLT was extracted from GLSP using ultrasonic extraction, and the obtained extract was concentrated in a rotary evaporator, then lyophilized and stored at $4^{\circ} \mathrm{C}$ for further analysis[23]. All chemicals and reagents used were of analytical grade.

\subsection{Preparation of electrospinning solutions}

A $20 \mathrm{wt} \%$ PCL solution was prepared by dissolved $5.25 \mathrm{~g}$ of PCL in $20 \mathrm{~mL}$ of glacial acetic acid. PEO solution was prepared by dissolving $0.3 \mathrm{~g}$ PEO in $10 \mathrm{~mL}$ aqueous solution of ethanol. Different concentrations of GLT ( $2 \mathrm{wt} \%, 4 \mathrm{wt} \%$ and $6 \mathrm{wt} \%$ ) was prepared by dissolving in glacial acetic acid and introducing this to the initial base PCL solution. $1 \mathrm{wt} \%$ MTX is added to the PEO solution to prepare the polymeric-drug solution. To obtain a homogenous, uniform solution, the suspension was continuously mixed at $300 \mathrm{rpm}$ using a magnetic stirrer for 12 hours at room temperature $\left(25^{\circ} \mathrm{C}\right)$.

\subsection{PEO-MTX / PCL-GLT Fiber Fabrication}

The experimental set up for coaxial electrospinning technology is shown in Fig. 1a. The experimental set-up consists of a high voltage power supply ( $0 \sim 30 \mathrm{kv}$, Glassman High Voltage Inc, USA), 2 syringe pumps (KD Scientific KDS100, USA) and a roller collector. The coaxially arranged processing needle comprised of an inner and outer needle. The inner/outer diameter of the inner and outer needle were $0.2 / 0.4 \mathrm{~mm}$ and $0.9 / 1.2 \mathrm{~mm}$, respectively.

The core formulation (PCL-GLT) was fed through the inner needle at flow rates $0.5-0.8 \mathrm{~mL} / \mathrm{h}$ whilst the shell formulation (PEO-MTX) was fed through the outer needle at a flow rate between 0.25 and 0.4 $\mathrm{mL} / \mathrm{h}$. A roller collector (diameter: $7 \mathrm{~cm}$, length: $14 \mathrm{~cm}$ ) was placed under the coaxial processing needle with a rotating speed of 1000-1400 rpm to collect the fabricated electrospun fibers. the vertical working distance between the needle exit and the roller was approximately $12 \mathrm{~cm}$. To show the formation of stable Taylor Cone jet, a preliminary electrospinning study was performed with a PCL-Rhodamine B solution being fed through the inner needle. All experiments were performed at the ambient temperature $\left(25^{\circ} \mathrm{C}\right)$.

\subsection{Fiber Morphology Assessment}

Optical Microscopy (OM, Phoenix BMC 503-ICCF, China), and Scanning Electron Microscopy (SEM, SEM, SU 8000 SEM, Hitachi, Japan) was utilised to examine the distribution and surface morphology of the resulting fibers. Before subjecting the fibrous structures to SEM analysis, the samples were mounted on a metal stub and were gold-coated under vacuum at a current intensity of $15 \mathrm{~mA}$ for 60 seconds. Fiber diameter analysis was performed on electron micrographs using Image $\mathrm{J}$ software 
(National Institute of Health, MD, USA). 100 random fibers were selected from each sample were calculated and plotted to decipher average fiber diameter. All statistical plots were drawn using Origin 2017 (OriginLab, USA).

\subsection{Fourier transform infrared (FTIR) spectroscopy}

To study excipient and fiber stability, the composition and intermolecular interactions of CESFM was analysed using an FTIR spectrometer (IR Affinity 1, Shimadzu, Japan). Samples were prepared using the $\mathrm{KBr}$ pellet method. Approximately $2 \mathrm{mg}$ of sample was mixed with approximately $200 \mathrm{mg} \mathrm{KBr}$ powder. The mixture was ground into a fine powder and was subsequently pressed into a transparent sheet using $20 \mathrm{MPa}$ of pressure using a powder compressor (FW-4A, Tianjin TUOPU instrument Co Ltd, Tianjin, China). The samples were scanned within the FTIR spectrum of 4000 to $400 \mathrm{~cm}^{-1}$ at a resolution of $4 \mathrm{~cm}^{-1}$ and from 20 scans.

\subsection{X-Ray Diffraction (XRD)}

An X-Ray diffractometer (Gemini A OHra, Oxford Varian, UK) was used to analyse the crystal configuration of the CESFM at room temperature $\left(25^{\circ} \mathrm{C}\right)$. The voltage and current were kept at $40 \mathrm{kV}$ and $30 \mathrm{~mA}$, respectively. The sample was scanned over a range from $3^{\circ}$ to $60^{\circ}$ over $2 \theta$ with step a change of $0.02^{\circ}$.

\subsection{Differential Scanning Calorimetry (DSC)}

DSC was utilised to study the thermal stability of the electrospun fibrous structures. A calorimeter (PE DSC 7, Perkin-Elmer, USA) was used. Sealed pans containing approximately $3 \mathrm{mg}$ of the sample were heated under a flow of nitrogen gas at a rate of $30{ }^{\circ} \mathrm{C} / \mathrm{min}$ from 30 to $400{ }^{\circ} \mathrm{C}$.

\subsection{Contact Angle Analysis}

The contact angle (CA) between a water droplet and a material/sample will elude to the degree of hydrophilicity of the test sample[24]. Here, a contact angle goniometer (SL2000KB, Kino Industry Co, Ltd, USA) was used to study the hydrophilic properties of the CESFM. $1 \mu \mathrm{L}$ water droplet is introduced to a glass slide on which the sample has been anchored too. The CA between the droplet and the sample is recorded for the first 10 sections following the introduction of the droplet. The experiment was carried out in drop mode at ambient temperatures. The experiment was repeated 5 times and an average was calculated.

2.9 Release of MTX and GLT from the coaxial fibers

\subsubsection{MTX Release}

To assess the in vitro release of MTX, the sample was immersed in a glass vial containing $10 \mathrm{~mL}$ phosphate buffer saline (PBS, $\mathrm{pH}=7.4)$ and this was placed into a gas bath thermostatic shaker $(100$ rpm) (DDHZ-300, Suzhou Peiying Experimental Equipment Co, Ltd, Suzhou, China) at $37{ }^{\circ} \mathrm{C}$. The 
masses of samples with triterpenoids content of $2 \mathrm{wt} \%, 4 \mathrm{wt} \%$, and $6 \mathrm{wt} \%$ were $4.14 \pm 0.036,6.63 \pm$ 0.012 , and $6.36 \pm 0.045 \mathrm{mg}$, respectively. At predetermined time points, $4 \mathrm{~mL}$ of sample release medium was removed and replaced with fresh medium. The removed samples were analysed using UV spectrophotometry (UV-2600 spectrophotometer, Shimadzu, Japan) at a wavelength of $303 \mathrm{~nm}$.

\subsubsection{GLT Release}

To assess the in vitro release of GLT, the sample was immersed in a glass vial and placed into a thermostatic shaker as above. At predetermined time points, $1 \mathrm{~mL}$ of the PBS release medium $(\mathrm{pH}=7.4)$ was removed and supplemented with $1 \mathrm{~mL}$ fresh PBS. The removed samples here were analysed using UV spectroscopy at a wavelength of $545 \mathrm{~nm}$.

\subsubsection{Drug Release, Loading Capacity and Encapsulation Efficiency}

The release rate of the drugs was calculated using Equation 1:

$$
\text { Drug release }(\%)=\frac{m_{t}}{m_{s}} \times 100
$$

$m_{t}$ is the weight of the drug (MTX or GLT) released at time point $t$ and $m_{s}$ is the sum of the weight of the drug released.

The loading capacity (LC) and encapsulation efficiency (EE) of MTX and GLT were evaluated to assess the packaging effect of the coaxial electrospinning process[25]. LC and EE were calculated using Equation 2 and Equation 3, respectively.

$$
\begin{aligned}
& \mathrm{LC}(\%)=\frac{\text { The total content of triterpenoids or methotrexate in the fibers }(\mathrm{mg})}{\text { Amount of fibers }(\mathrm{mg})} \times 100 \% \\
& \mathrm{EE}(\%)=\frac{\text { The total content of triterpenoids or methotrexate in the fibers }(\mathrm{mg})}{\text { Theoretical total amount of triterpenoids or methotrexate }(\mathrm{mg})} \times 100 \%
\end{aligned}
$$

The release kinetics of each active was also evaluated; fitting the in vitro release data into various kinetic models (Zero-order, first-order, Higuchi and Korsmeyer-Peppas) to determine the mechanism of release of GLT and MTX in a simulated neutral environment $(\mathrm{pH}=7.4)$. The model with the highest correlation coefficient $\left(\mathrm{R}^{2}\right)$ was considered the best fit model.

\subsection{Inhibition of Cervical cancer cells (HeLa)}

Any potential anti-cancer effect of the fabricated CESFM on Hela cells were studied. The HeLa cells were cultured in Dulbecco's modified Eagle's medium (DMEM, Corning, USA) supplemented with 
$10 \%$ fetal bovine serum (FBS, Gibco) and 1\% Antibiotics (penicillin $100 \mathrm{U} / \mathrm{mL}$ and streptomycin 100 $\mu \mathrm{g} / \mathrm{mL})$. The cells were cultured in a $5 \% \mathrm{CO}_{2}$ incubator at $37^{\circ} \mathrm{C}$.

The effect of the fabricated CESFEM on HeLa cell viability was also investigated using a CCK-8 assay. The formulations tested were: CESFEM containing $1 \mathrm{wt} \%$ MTX, CESFEM containing $1 \mathrm{wt} \%$ MTX and GLT concentrations of $2 \mathrm{wt} \%, 4 \mathrm{wt} \%$, and $6 \mathrm{wt} \%$. These four formulations were introduced to DMEM medium and were left to release for one week. Then $100 \mu \mathrm{L}$ of Hela cells (logarithmic growth phase) were introduced into a 96-well plate, cultured for 24 hours to allow their attachment to walls. The original medium was removed, and the drug-containing medium was changed, and cultured for 24 hours. After 24 hours, the previous medium was removed, the medium was mixed with the CCK-8 solution at a ratio of $10: 1$, and $100 \mu \mathrm{L}$ of the mixture was added to each well, and the 96-well plate was cultured in an incubator.

The samples from the well plate were analysed using absorbance microplate reader. The cell survival rate was calculated using Equation 4:

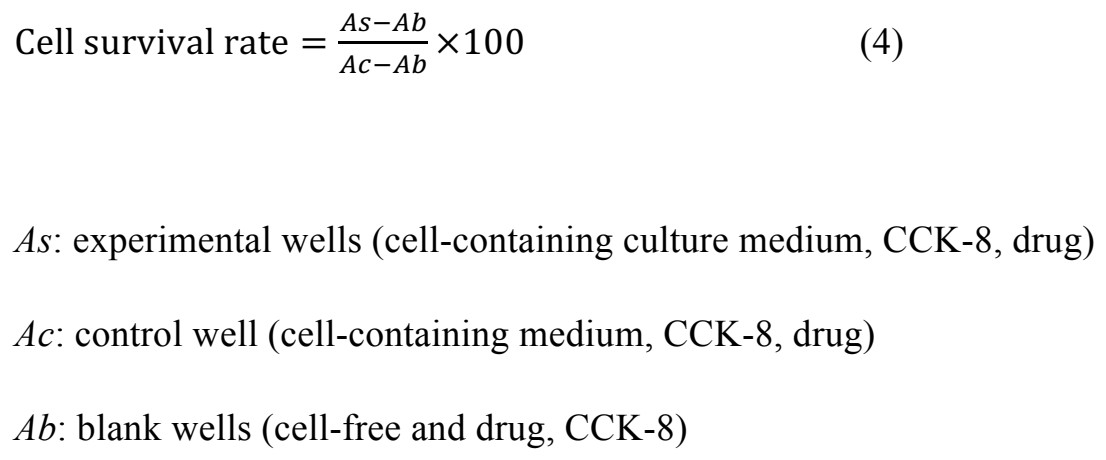

As: experimental wells (cell-containing culture medium, CCK-8, drug)

$A c$ : control well (cell-containing medium, CCK-8, drug)

$A b$ : blank wells (cell-free and drug, CCK-8)

To observe the effect of CESFM on the HeLa cells, Alexa Fluor 546 phalloidin (P) (Invitrogen, California, USA) and 4',6'-diamidino-2 phenylindole hydrochloride (DAPI) were used to strain the cytoskeleton and nuclei of the cells, respectively. The cell suspension $\left(1.1 \times 10^{5}\right.$ cells $)$ were inoculated onto petri dish into which the CESFM samples with various drug concentrations were introduced. These petri dishes were then cultured in an incubator for 48 hours. The cells were then rinsed with PBS and $4 \%$ paraformaldehyde was added. This mixture was then stirred for 60 minutes at $60 \mathrm{rpm} .0 .1 \%$ Triton was then introduced to the cells and this was stirred for a further 5 minutes at $60 \mathrm{rpm}$. The cells were then rinsed again 3 times with PBS and were subsequently stained with P (cytoskeleton for 20 mins) and DAPI (nuclei for 60 mins). The final stained cells were then observed under a fluorescent microscope.

\subsection{Statistical Analysis}


All experiments were performed in triplicate, with results being expressed as mean \pm standard deviation. Statistical analysis was performed using Origin Pro 2017 and Excel 2016. The t-test was used to calculate the $p$ value and $p<0.05$ was considered significant.

\section{Results and Discussion}

\subsection{Fabrication and Characterisation of PEO-MTX/PLC-GLT Fibers}

Here, coaxial electrospinning technology was utilised to engineer a fibrous membrane containing bioactive MTX and GLT. The physical liquid parameters (viscosity, density, electroconductivity) and electrospinning process parameters (flow rate, applied voltage, collection distance) greatly affect the spin ability of the formulation and the stability of the resulting fibers[13].

In order to observe the inner and outer solution in jetting mode, Rhodamine B was introduced to the PCL solution. In Fig. 1b, before the voltage was applied, a droplet with a red inner core can be observed at the needle exit. The colour difference between the PCL core and PEO shell indicates the encapsulation of PCL. When the voltage was increased to $6 \mathrm{kV}$, gravitational and electrostatic forces causes the droplet to be stretch. Increasing the voltage to $11 \mathrm{kV}$, the liquid began to form a jet (Fig. 1c). Fig. 2 displays the fluorescence micrograph of the resulting core-shell fiber. It is clear to see two distinctive layers; with a red inner layer confirming the successful formation of core-shell structure using coaxially arranged processing needles.

\subsection{Morphology of CESFM}

Fig. 3 shows the optical images (Fig. 3a1, b1, c1), electron micrographs (Fig. 3a2, b2, c2) and fiber diameter distribution (Fig. 3a3, b3 and c3) of the various CESFM samples. The optical images and SEM images show that all CESFM samples presented uniformly and well orientated fibers. The resulting structures presented a smooth surface morphology and cylindrical structures. As the concentration of triterpenoids increased, the fiber diameter increased and the fibers became more evenly distributed. The average diameter of electrospun fibers with GLT concentrations of $2 \mathrm{wt} \%, 4 \mathrm{wt} \%$ and $6 \mathrm{wt} \%$ were $2.29 \pm 1.26 \mu \mathrm{m}, 3.30 \pm 2.25 \mu \mathrm{m}$ and $4.65 \pm 2.30 \mu \mathrm{m}$, respectively. This increase in diameter may be due to increase in viscosity and decrease in conductivity as a result of increase in triterpenoids[26].

\subsection{FTIR Spectroscopy and XRD Analysis}

To evaluate and assess the composition and stability of the fiber matrices, FTIR spectroscopy was carried out. Fig. 4a shows the FTIR spectroscopy fingerprints of raw PCL, PEO, raw bioactive and the resulting engineered membrane. The strong peak at $2900 \mathrm{~cm}^{-1}$ in the FTIR spectra for pure PEO corresponds to the stretching mode of $\mathrm{CH}[27]$ while the peak at $1954 \mathrm{~cm}^{-1}$ corresponds to the asymmetric stretching of $\mathrm{CH}[28]$. The peak at $1350 \mathrm{~cm}^{-1}$ is due to the swinging of the $\mathrm{CH}_{2}$ bond and 
the peak at $1100 \mathrm{~cm}^{-1}$ is due to COC stretching[29]. The peaks at $960 \mathrm{~cm}^{-1}$ and $840 \mathrm{~cm}^{-1}$ corresponds to the $\mathrm{CH}_{2} \mathrm{CH}_{2}$ swing and $\mathrm{CH}_{2}$ swing, respectively[29]. The characteristic peaks at $2900 \mathrm{~cm}^{-1}, 1800 \mathrm{~cm}^{-1}$ and $1400 \mathrm{~cm}^{-1}$ which can be observed in the FTIR spectrum for PCL are due to the tensile vibrations of the $\mathrm{C}-\mathrm{H}, \mathrm{CO}$ and $\mathrm{C}-\mathrm{O}$ bonds in PCL[30]. Pure MTX showed symmetrical and asymmetric tensile vibrations of COO- (vCOO-) at 1373 and $1554 \mathrm{~cm}^{-1}$, respectively[31]. The absorption peaks of triterpenoids in the spectrum are mainly at $1050 \mathrm{~cm}^{-1}$ (-OH group), $1740 \mathrm{~cm}^{-1}$ to $1760 \mathrm{~cm}^{-1}$ (fivemembered cyclic ketone), $1720 \mathrm{~cm}^{-1}$ (ester), $1710 \mathrm{~cm}^{-1}$ (six-membered ring) Ketone), $1650 \mathrm{~cm}^{-1}$ ( $\alpha$, $\beta$ unsaturated ketone)[32]. In the spectrum of CEFSM the peak positions of triterpenoids changed. This is most likely due to the interaction between the compound molecules and it can also indicate that the drug was successfully encapsulated within the fiber matrix.

XRD analysis was carried out to examine the crystal structures and physical changes (if any) of the drugs and polymers before and after electrohydrodynamic processing. It can be observed from the peaks in Figure $4 \mathrm{~b}$ that the triterpenoids exist in amorphous form [33]. The peak seen between $2 \theta=10^{\circ}$ and $30^{\circ}$ for MTX is consistent with results found in literature [34]. Both polymers showed two distinct peaks: $2 \theta=19.16^{\circ}$ and $2 \theta=23.34^{\circ}$ for PEO[35] and $2 \theta=21.38^{\circ}$ and $2 \theta=23.82^{\circ}$ for PCL indicating the crystal properties of PCL[36]. No significant difference between the XRD patterns of the CESFM and the pure polymers highlighting the even distribution of both drugs. The existence of drugs in amorphous form shows desirable advantages including high solubility, fast dissolution rate, and easy absorption by the human body [37].

\subsection{Differential Scanning Calorimetry (DSC) Analysis}

The thermal behaviour of the materials and samples was assessed using DSC. Fig. 5 shows the resulting DSC thermograms. A single endothermic peak can be observed in each of the thermograms for pure polymers and drugs. These peaks, seen at $69.7^{\circ} \mathrm{C}, 58{ }^{\circ} \mathrm{C}$ and $131.3^{\circ} \mathrm{C}$ for PEO, PCL and MTX, respectively, all correspond to melting points. It can be seen from the figure that the peak of triterpenoids was broad. The CESFM thermogram shows two endothermic peaks, which are the peaks of PCL and PEO. The absence of the strong endothermic peaks of MTX and triterpenoids in the CESFM thermogram proves the two drugs are present in the amorphous state in the electrospun fibers[38]. These DSC curves also highlight that fiber production and drug encapsulation here is successful at ambient temperatures; which is advantageous for thermo-sensitive/thermo-labile materials or actives.

\subsection{Contact Angle Hysteresis}

It is important to identify the hydrophilicity of a material as this can greatly affect biological application and drug release kinetics[39]. Fig. 6 shows the resulting surface hydrophilicity data collected from contact angle studies. The CA of each fibrous sample was measured from 0s to 10s. After 10 seconds the CA of each sample was recorded to be $7.25 \pm 0.11,7.83 \pm 0.07$, and $9.27 \pm 0.18^{\circ}$ for CESFM containing $2 \mathrm{wt} \%, 4 \mathrm{wt} \%$ and $6 \mathrm{wt} \%$ triterpenoids, respectively. These low values suggest the fibrous 
membranes were hydrophilic. According to previous work in this field[40], PEO is a hydrophilic material and being the outer shell material of the bilayer fibers fabricated here, the low CA values were expected. The slight differences in CA are a result of the differences in GLT content. Triterpenoids are polar compounds[41] hence the higher the concentration the higher the concentration of water molecules will prevent diffusion. When the triterpenoid concentration increased from $2 \mathrm{wt} \%$ to $6 \mathrm{wt} \%$ in 10 secs, there was no significant difference in the hydrophilicity of the CESFM. The size distribution and surface morphology of electrospun fibers are contribute to their hydrophilicity. The rough and uneven surface of the fiber will cause hydrophobicity[42]. As GLT concentration increased, the fiber diameter increases and surface becomes more rough resulting in decreased hydrophilicity.

\subsection{In Vitro Drug Release}

Compared to conventional encapsulation technologies such as dispersion and emulsification, coaxial electrospinning is more effective and economical for producing core-shell structures capable of achieving high LC and EE[43]. Fig. 7 shows the LC and EE that were calculated. The LC represents the mass of MTX or GLT coated per unit fiber mass. The EE is the ratio of the total drug mass added to the mass of drug effectively encapsulated in the fiber and the effectiveness of the coaxially arranged fibers. When triterpenoid concentration increased from $2 \mathrm{wt} \%$ to $6 \mathrm{wt} \%$, the LC of MTX increased from $0.63 \pm 0.01 \%$ to $0.71 \pm 0.01 \%$ and EE increased from $62.9 \pm 0.5 \%$ to $72.1 \pm 0.6 \%$ (Fig. 7a). GLT followed the same patterns (Fig. 7b). As concentration increased, triterpenoid LC increased from 0.20 $\pm 0.0013 \%$ to $0.72 \pm 0.0042 \%$. EE also increased from $9.77 \pm 0.07 \%$ to $14.92 \pm 0.070 \%$. The ultimate conclusion from this study shows that triterpenoid concentration can improve LC and EE.

In vitro drug release experiments were carried out using PBS solutions over 7 days. The experimental results can be seen in Fig. 8. In the first hour, the release of MTX from the CESFM containing 2 wt\% GLT reached $75 \%$ whilst only $33 \%$ of GLT was release (Fig. 8a1). After 24 hours, MTX release was $87 \%$ while triterpenoid release reached $73 \%$. When GTL concentration was increased to $4 \mathrm{wt} \%$ (Fig. 8b1) and $6 \mathrm{wt} \%$ (Fig. 8c1), no significant differences could be observed compared to concentration of $2 \mathrm{wt} \%$. This release study indicated that MTX was released in a biphasic manner; showing an initial burst release followed by a slower release phase. In contrast, the release of triterpenoids appeared to be much slower. This is most likely due to the fact that GLT was encapsulated in the inner core of the electrospun fibers. With PCL forming a large majority of this inner layer, the hydrophobicity of this layer contributes to the slow release of the encapsulated GLT[15]. The two different release profiles from MTX and GLT allows them to provide a good synergistic anti-cancer effect. Table 1 shows the resulting curves when the in vitro drug release data was fitted to various release kinetic models. As shown in Table 1, both bioactive showed release via Fick diffusion from the CESFM; proven by the high correlation coefficient that was demonstrated by Korsmeyer-Peppas model with a $n$ value less than 0.45 . 


\subsection{Anti-Cancer effects on cervical cancer cells (HeLa)}

Previous literature in this field have shown that GLT possess advantageous anti-cancer effects[44]. This study was carried out to assess the effects of coaxially electrospun fibers encapsulation with triterpenoids and MTX on HeLa cells were studied. CCK-8 experiments were performed using HeLa cells. The experimental results are shown in Fig. 9. The cell survival rate of the fiber membrane loaded with only MTX. $79.90 \pm 1.12 \%$ (in 24 hours). The cell survival rates were $72.89 \pm 2.54 \%, 70.28 \pm$ $2.05 \%$ and $67.42 \pm 1.24 \%$, for GLT concentrations $2 \mathrm{wt} \%, 4 \mathrm{wt} \%$ ad $6 \mathrm{wt} \%$, respectively. The general trend saw that the higher the triterpenoids concentration, the more enhanced the anti-cancer effect. Moreover, when triterpenoid concentration was increased to $6 \mathrm{wt} \%$, the cell survival rate decreased by $12.48 \%$ compared to CESFM containing MTX only.

Studies have shown that GLT extract inhibits the growth of HeLa cells by inhibiting the cell cycle and cell signal transduction by changing the calcium transport system[45]. Experiments have shown that GLT can directly and indirectly kill tumor cells whilst activating G0 tumor cells which are difficult to kill by chemotherapy drugs for separate and combined killing effects[46]. The unique effect of GLT on G0 phase cells and the effective suppression of recurrence and metastasis of malignant tumor make up for the deficiency of traditional tumor treatment (i.e. surgery, radiotherapy, chemotherapy) and become the main force in tumor immunotherapy. However, the experimental results demonstrate that the synergistic anticancer effect of MTX and GLT can pave a new combination for fiber based therapeutics.

Fig. 10 shows a fluorescently stained image of the effect of CESFM on the morphology of HeLa cells. As seen in Fig. 10, the cells showed an irregular spindle-like morphology, and the morphology of the cells treated with the coaxial electrospun fiber membrane was not significantly different from the control (Fig. 10a1, a2). When treated with a fiber membrane containing only MTX (Fig. 10b1, b2), cell density becomes smaller, further indicating that the treatment group has a certain anti-cancer effect on the cells. The results are similar to those of the cell viability study when treated with fiber membranes with different concentrations of triterpenoids ( $2 \mathrm{wt} \%, 4 \mathrm{wt} \%$ and $6 \mathrm{wt} \%$ ) (Fig. 10c1-e2). The cell density decreased significantly compared to the control, indicating that it had a significant inhibitory effect on the HeLa cells. Therefore, as an effective chemotherapy drug for human cervical cancer, the CESFM has broad prospects.

\section{Conclusion}

Core-shell drug-loaded fiber membranes were successfully prepared here via coaxial electrohydrodynamic spinning technology. MTX was encapsulated in PEO shell layer while GLT was loaded in the PCL core layer. Fluorescence microscopy confirmed the structure of the core-shell fibers and SEM analysis showed the resulting fibers were cylindrical in shape and had good alignment. FTIR spectroscopy, DSC and XRD showed that both drugs presented in amorphous form, were uniformly 
dispersed and were successfully encapsulated within the polymer core-shell matrix. The in vitro release studies showed biphasic MTX release and slow GLT release. In vitro cell experiments showed both drugs had a synergistic effect on inhibitory effect of HeLa cells. The coaxial electrospinning method used here is a simple, easy to operate process which allows structures with controlled morphology to be fabricated whilst enabling the combination of Chinese and western medicine in single step for the treatment of cervical cancer.

\section{Declaration of competing interest}

The authors have no conflict of interest to declare

\section{Acknowledgements}

This work was financially supported by the National Nature Science Foundation of China (No.81301304), the Fundamental Research Funds for the Central Universities (2019QNA5027), and the Key Technologies R\&D Program of Zhejiang Province (2015C02035). 
Tables and Figures

Table 1. Drug release simulation of methotrexate and triterpenoids.

\begin{tabular}{|c|c|c|c|c|}
\hline \multirow{2}{*}{$\begin{array}{l}\text { Simulation } \\
\text { model }\end{array}$} & \multicolumn{2}{|l|}{ Methotrexate } & \multicolumn{2}{|l|}{ Triterpenoids } \\
\hline & Equation & $\mathrm{R}^{2}$ & Equation & $\mathrm{R}^{2}$ \\
\hline Zero order & $\mathrm{R}_{\mathrm{t}}=73.87+0.6923 \mathrm{t}$ & 0.945 & $\mathrm{R}_{\mathrm{t}}=27.98+5.789 \mathrm{t}$ & 0.9642 \\
\hline First order & $\begin{array}{l}\lg \left(1-R_{t}\right)=-0.01217- \\
0.5826 t\end{array}$ & 0.9518 & $\begin{array}{l}\lg \left(1-R_{t}\right)=-0.1375- \\
0.04299 t\end{array}$ & 0.9799 \\
\hline Higuchi & $\mathrm{R}_{\mathrm{t}}=72.69+1.924 \mathrm{t}^{0.5}$ & 0.9845 & $\mathrm{R}_{\mathrm{t}}=18.25+15.97 \mathrm{t}^{0.5}$ & 0.9902 \\
\hline $\begin{array}{l}\text { Korsmeyer- } \\
\text { Peppas }\end{array}$ & $\lg R_{t}=1.873+0.01601 \operatorname{lgt}$ & 0.9941 & $\lg R_{t}=1.539+0.2593 \operatorname{lgt}$ & 0.9924 \\
\hline
\end{tabular}


Fig. 1. (a) Schematic diagram of the coaxial electrospinning set-up system, and digital images of the coaxial filament jet at applied voltage (b) $0 \mathrm{kV}$ and (c) $11 \mathrm{kV}$.

Fig. 2. The fluorescence microscope image of CESFM. (Inner layer was stained with Rhodamine B).

Fig. 3. Optical micrographs (a1, b1, c1), scanning electron micrographs (a2, b2, c2) and diameter distribution diagrams $(\mathbf{a 3}, \mathbf{b 3}, \mathbf{c 3})$ of CESFM loaded with methotrexate and triterpenoids. The methotrexate concentration was $1 \mathrm{wt} \%$ in all three samples, and triterpenoid concentration was a1-a3 2wt\%; b1-b3: 4wt $\%$; c1-c3: $6 \mathrm{wt} \%$.

Fig. 4. (a) FTIR spectra and (b) XRD patterns of coaxial electrospun fiber membranes loaded with methotrexate and triterpenoids, raw polymer materials and pure drugs.

Fig. 5. DSC curves of pure PEO, PCL, methotrexate, triterpenoids and coaxial electrospun fiber membranes (CESFM) loaded with methotrexate and triterpenoids.

Fig. 6. Image of water contact angle of fiber membrane at different time points: $0 \mathrm{~s}, 5 \mathrm{~s}$ and 10 s. The three colours in the figure indicate three different samples, of which the triterpenoid content is $2 \mathrm{wt} \%, 4 \mathrm{wt} \%$, and $6 \mathrm{wt} \%$, respectively. ${ }^{*} p<0.05$, ${ }^{* *} p<0.01$, data represented as mean $\pm \mathrm{SD}, n=3$.

Fig. 7. Loading capacity and encapsulation efficiency of methotrexate (a) and triterpenoids (b) in CESFM. Samples refer to CESFM with triterpenoids contents of $2 \mathrm{wt} \%$, $4 \mathrm{wt} \%$, and $6 \mathrm{wt} \%$, respectively. Data represented as mean $\pm \mathrm{SD}, \mathrm{n}=3$.

Fig. 8. Release kinetic curves of methotrexate and triterpenoids release from CESFM in PBS solution. a1, b1, c1: Release curve in the first 12 hours; a2, b2, c2: Release curve in the first 7 days. a1, a2: triterpenoids' concentration was $2 \mathrm{wt} \%$; b1, b2: triterpenoids' concentration was 4 wt $\%$; c1, c2: triterpenoids' concentration was $6 \mathrm{wt} \%$. Data represented as mean $\pm \mathrm{SD}, \mathrm{n}=3$.

Fig. 9. Effect of methotrexate and triterpenoids on cell viability of Hela Cells. $* p<0.05$, $* * p<0.01$, data represented as mean $\pm \mathrm{SD}, n=7$. Treatment with drugs for 24 hours.

Fig. 10. Fluorescence photomicrograph of HeLa cells (after adding CESFM, culture for 48 hours). a1, a2: Control (untreated, no fiber membrane added); b1, b2: CESFM (1 wt $\%$ methotrexate); c1, c2: CESFM (1 wt $\%$ methotrexate, $2 \mathrm{wt} \%$ triterpenoids); d1, d2: CESFM (1 wt $\%$ methotrexate, $4 \mathrm{wt} \%$ triterpenoids); e1, e2: CESFM (1 wt $\%$ methotrexate, $6 \mathrm{wt} \%$ triterpenoids). 
(a)
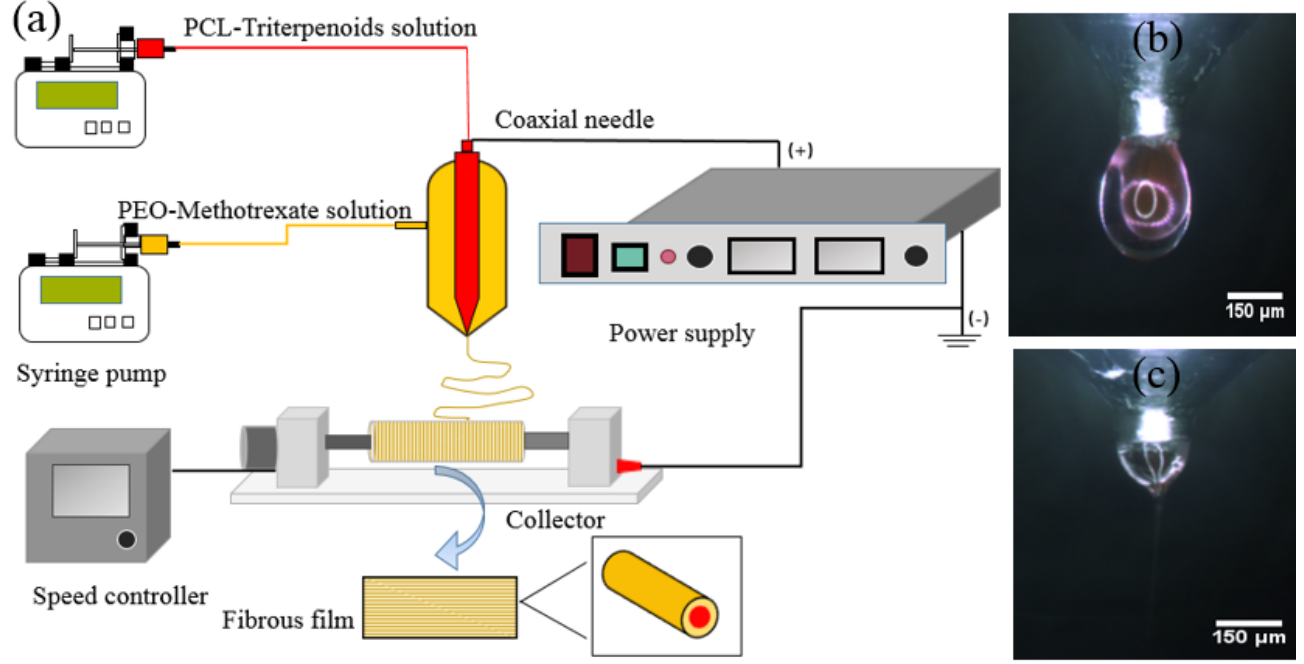

Figure 1

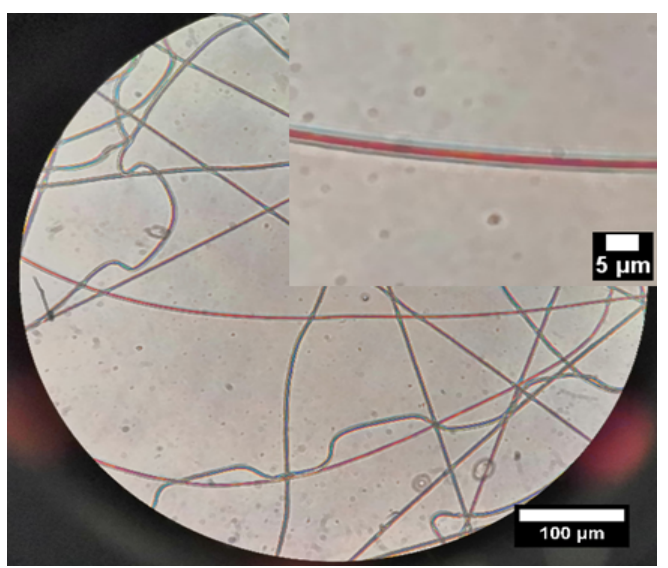

Figure 2 

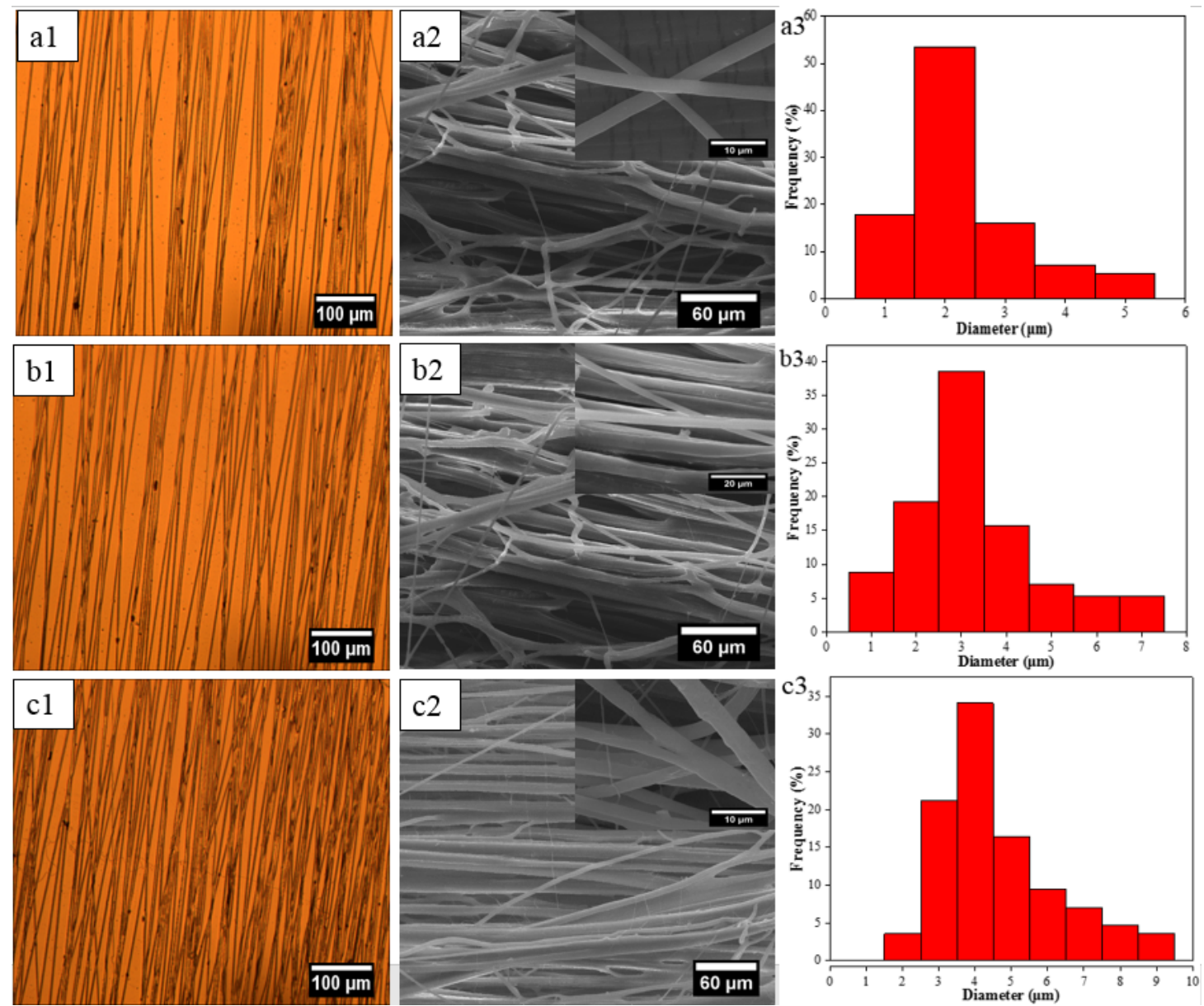

Figure 3 

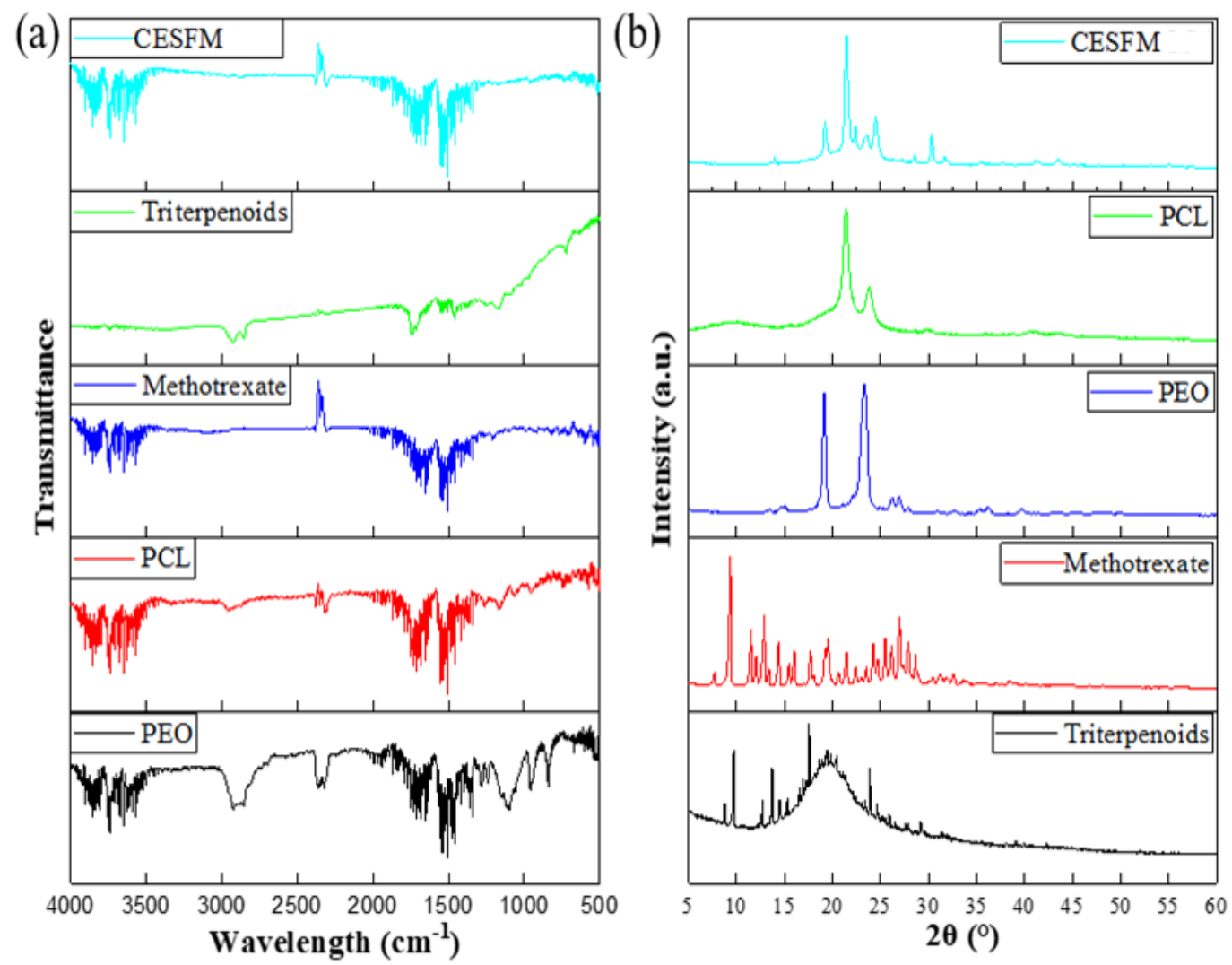

Figure 4

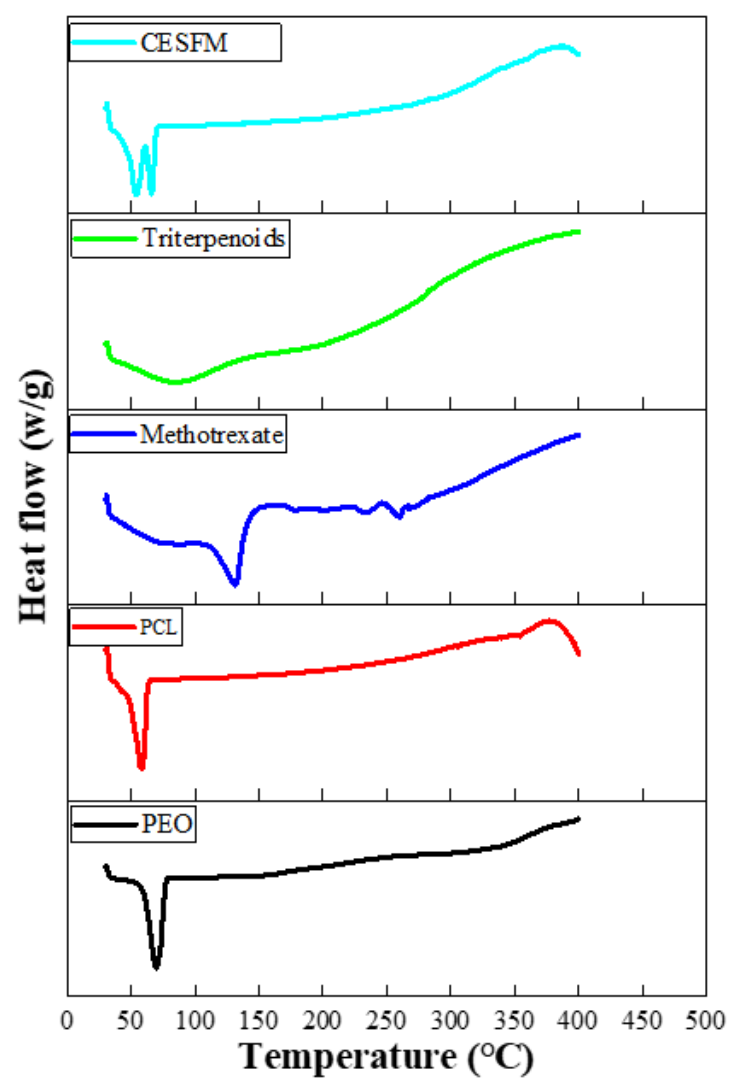

Figure 5 


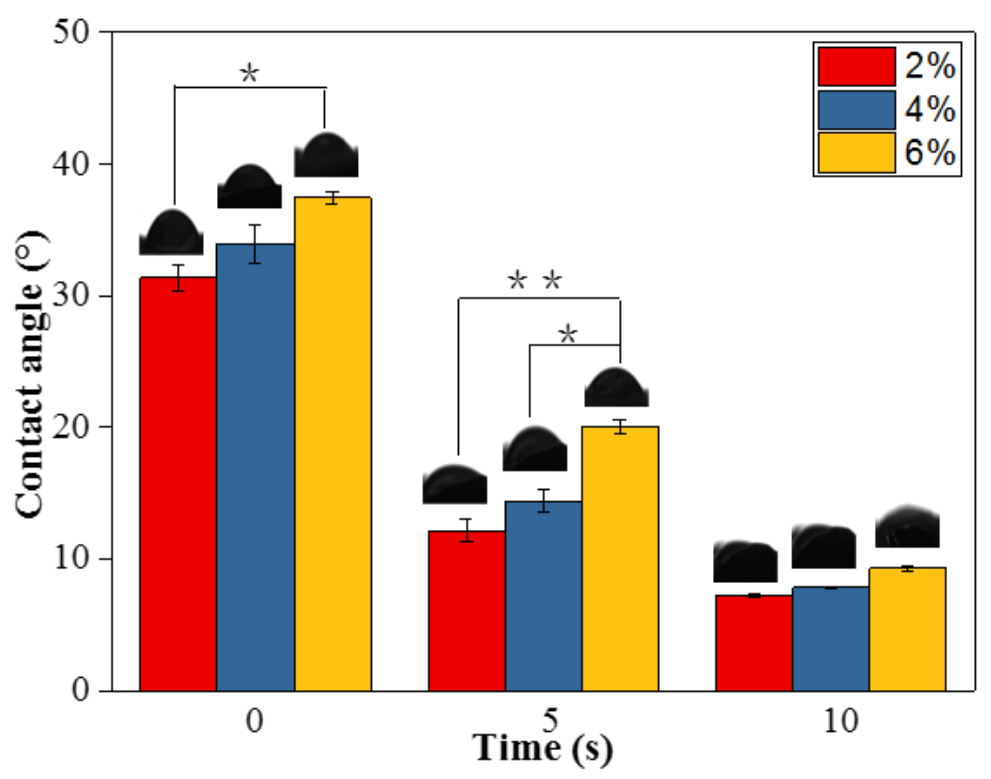

Figure 6 

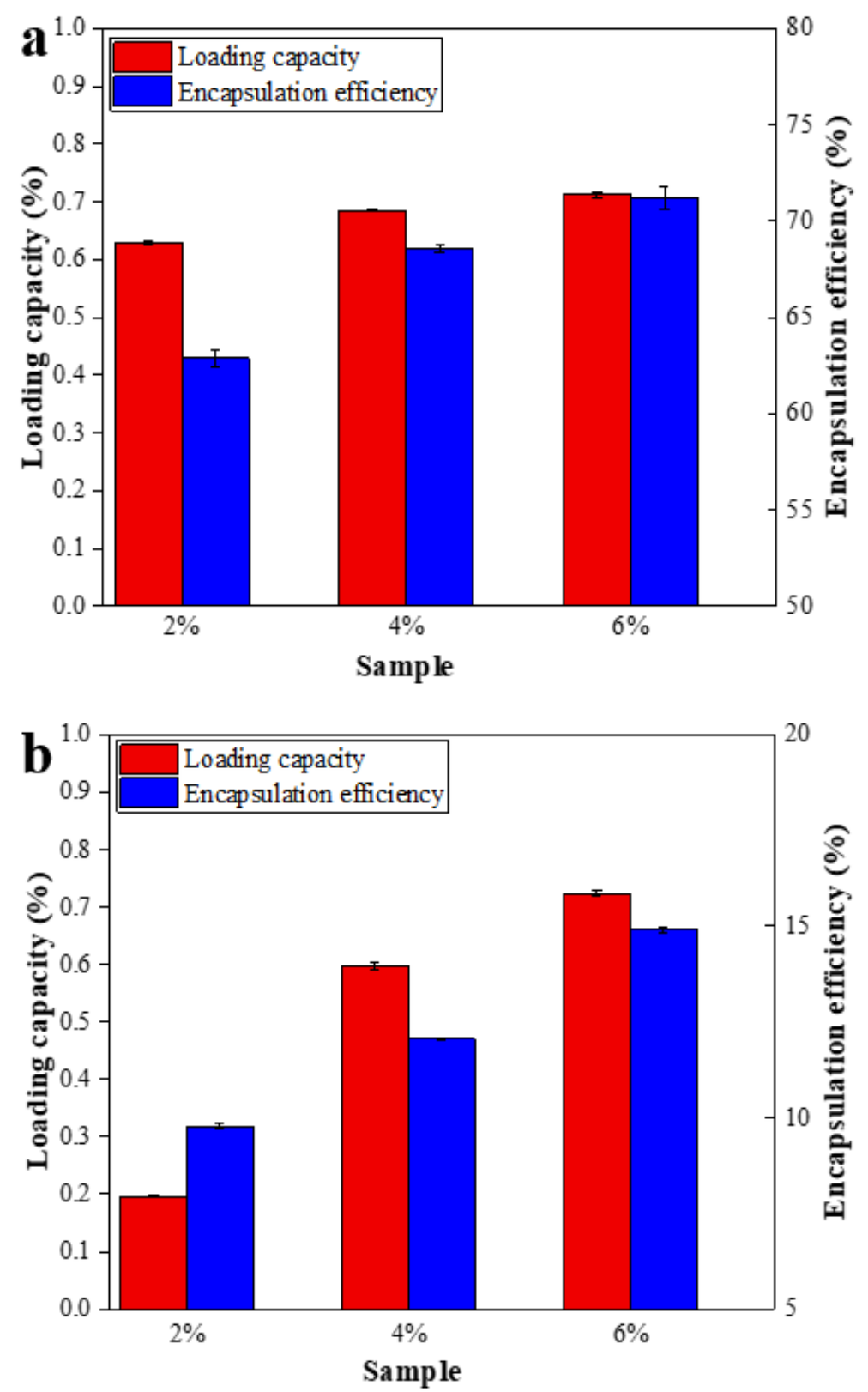

Figure 7 

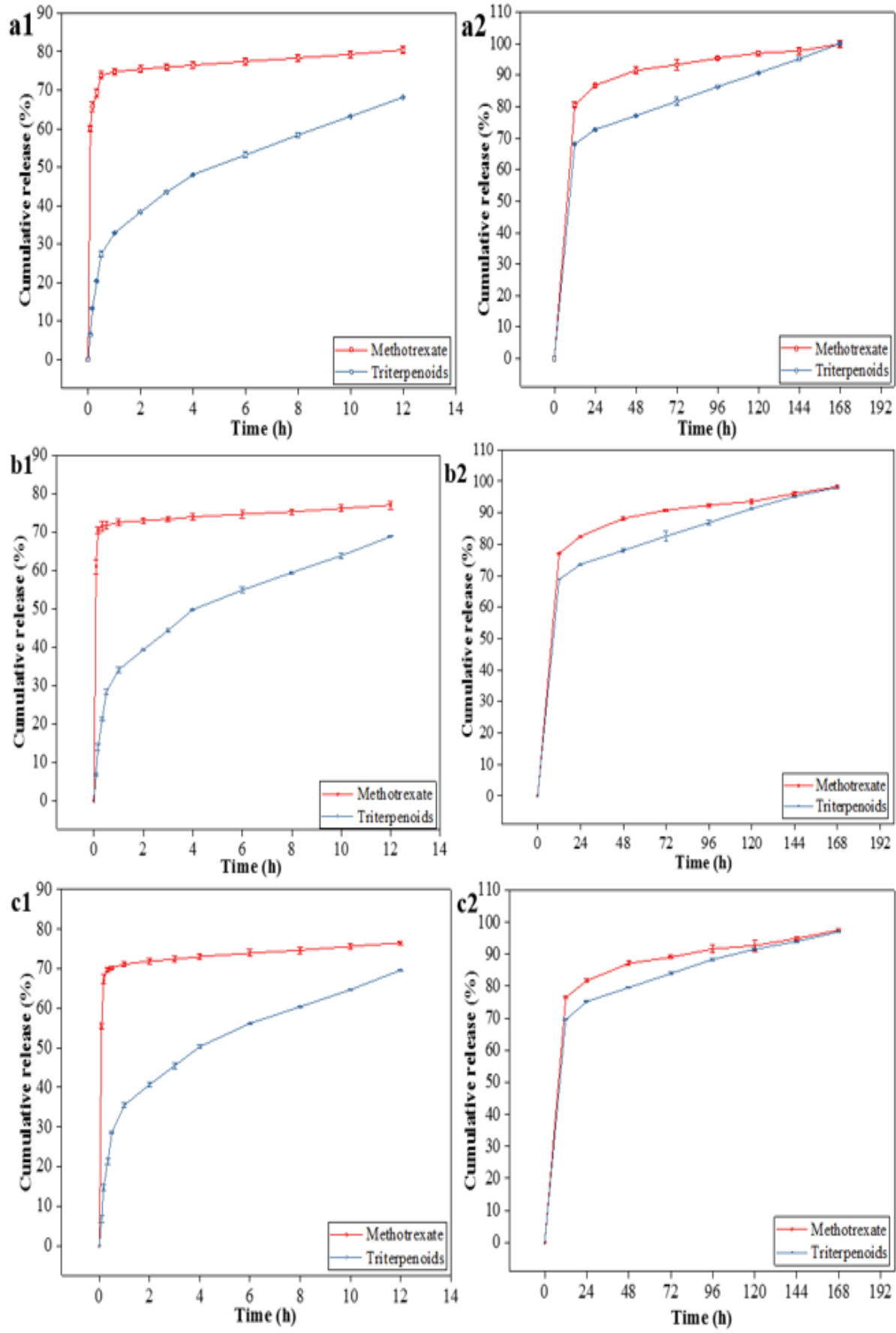

Figure 8 


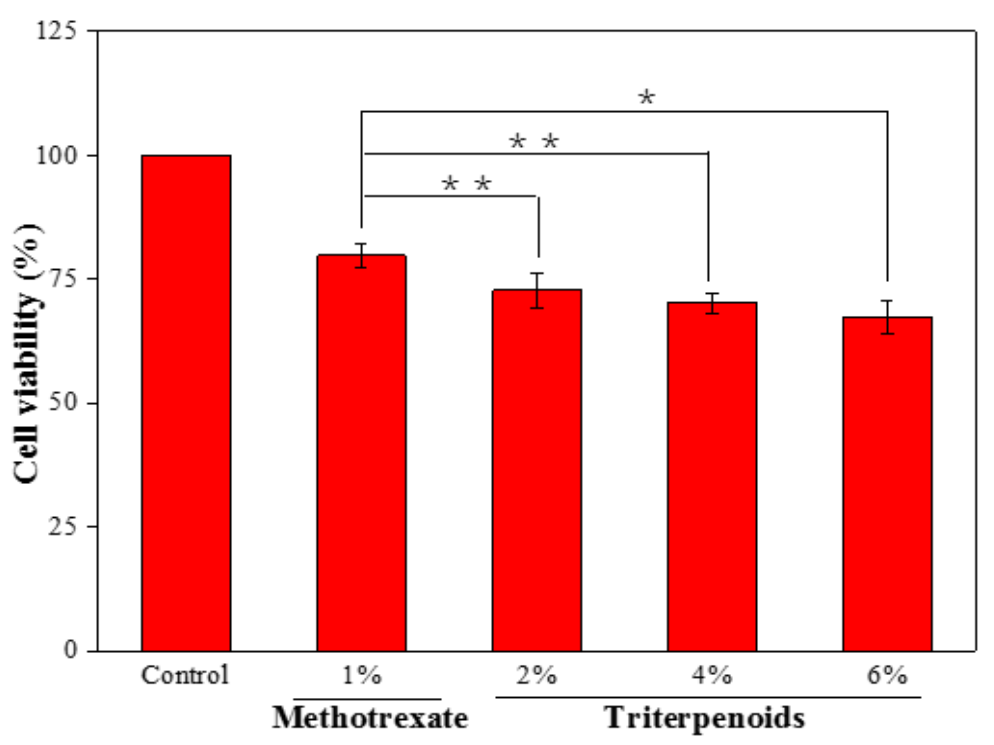

Figure 9 

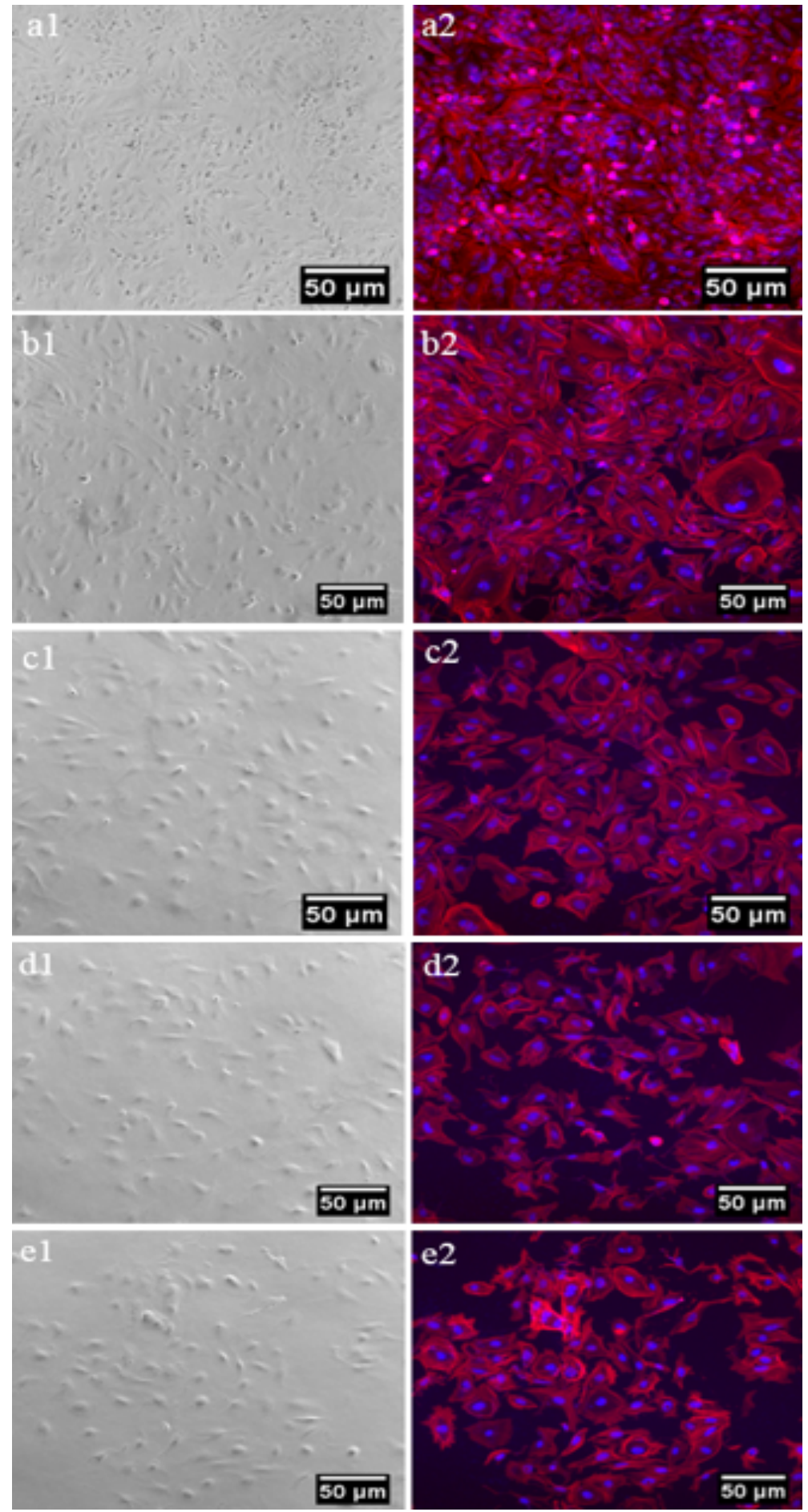

Figure 10 


\section{References}

[1] D. Duvnjak, M. Pantić, V. Pavlović, V. Nedović, S. Lević, D. Matijašević, A. Sknepnek, M. Nikšić, Advances in batch culture fermented coriolus versicolor medicinal mushroom for the production of antibacterial compounds, Innovative Food Science \& Emerging Technologies, 34 (2016) 1-8.

[2] H.J. Li, Y.L. He, D.H. Zhang, T.H. Yue, L.X. Jiang, N. Li, J.W. Xu, Enhancement of ganoderic acid production by constitutively expressing Vitreoscilla hemoglobin gene in Ganoderma lucidum, Journal of Biotechnology, 227 (2016) 35-40.

[3] U. Supratman, W. Naibaho, S. Salam, R. Maharani, A.T. Hidayat, D. Harneti, Nurlelasari, Y. Shiono, Cytotoxic triterpenoids from the bark of chisocheton patens blume (Meliaceae), Phytochemistry Letters, 30 (2019) 81-87.

[4] R. Xu, G.C. Fazio, S.P.T. Matsuda, On the origins of triterpenoid skeletal diversity, Phytochemistry, 65 (2004) 261-291.

[5] A. Tonelli, A. Candiani, M. Sozzi, A. Zucchelli, R. Foresti, C. Dall'Asta, S. Selleri, A. Cucinotta, The geek and the chemist: antioxidant capacity measurements by DPPH assay in beverages using open source tools, consumer electronics and $3 \mathrm{D}$ printing, Sensors and Actuators B: Chemical, 282 (2019) 559-566.

[6] G.Y. Jang, E.M. Joung, S.H. Lee, J.-H. Jeong, B.Y. Hwang, J.T. Hong, J. Lee, H.S. Jeong, Isolation and identification of antiproliferative substances from ginseng fermented using Ganoderma lucidummycelia, Food Science \& Biotechnology 24 (2015) 567-574.

[7] T.P. Smina, J. Mathew, K.K. Janardhanan, T.P.A. Devasagayam, Antioxidant activity and toxicity profile of total triterpenes isolated from Ganoderma lucidum (Fr.) P. Karst occurring in South India, Environmental Toxicology and Pharmacology, 32 (2011) 438-446.

[8] N. Maftoonazad, M. Shahamirian, D. John, H. Ramaswamy, Development and evaluation of antibacterial electrospun pea protein isolate-polyvinyl alcohol nanocomposite mats incorporated with cinnamaldehyde, Materials Science and Engineering: C, 94 (2019) 393-402.

[9] L. Zhu, Y. Zheng, J. Fan, Y. Yao, Z. Ahmad, M. Chang, A novel core-shell nanofiber drug delivery system intended for the synergistic treatment of melanoma, European Journal of Pharmaceutical Sciences, 137 (2019) 105002.

[10] S. Wu, B. Wang, Z. Ahmad, J. Huang, M. Chang, J. Li, Surface modified electrospun porous magnetic hollow fibers using secondary downstream collection solvent contouring, Materials Letters, 204 (2017) 73-76.

[11] Z. Yao, S.C. Chen, Z. Ahmad, H. Jie, J.S. Li, Essential oil bioactive fibrous membranes prepared via coaxial electrospinning, Journal of Food Science, 82 (2017) 1412-1422.

[12] A. Greiner, J.H. Wendorff, Electrospinning: a fascinating method for the preparation of ultrathin fibers, Angewandte Chemie, 46 (2010) 5670-5703.

[13] E.C.B. Noyan, E. Onder, N. Sarier, R. Arat, Development of heat storing poly(acrylonitrile) nanofibers by coaxial electrospinning, Thermochimica Acta, 662 (2018) 135-148.

[14] Z. Yao, Y. Gao, M. Chang, Z. Ahmad, J. Li, Regulating poly-caprolactone fiber characteristics in-situ during one-step coaxial electrospinning via enveloping liquids, Materials Letters, 183 (2016) 202-206.

[15] B.Y. Tay, S.X. Zhang, M.H. Myint, F.L. Ng, M. Chandrasekaran, L.K.A. Tan, Processing of polycaprolactone porous structure for scaffold development, Journal of Materials Processing Technology, 182 (2007) 117-121. 
[16] B. Azimi, P. Nourpanah, M. Rabiee, S. Arbab, Poly ( $€$-caprolactone) fiber: an overview, Journal of engineered fibers and fabrics, 9 (2014) 74-90.

[17] Y. Gao, D. Zhao, M. Chang, Z. Ahmad, X. Li, H. Suo, J. Li, Morphology control of electrosprayed core-shell particles via collection media variation, Materials Letters, 146 (2015) 59-64.

[18] I. Peinado, M. Mason, A. Romano, F. Biasioli, M. Scampicchio, Stability of $\beta$-carotene in polyethylene oxide electrospun nanofibers, Applied Surface Science, 370 (2016) 111-116.

[19] A.M. Moydeen, M.S. Ali Padusha, E.F. Aboelfetoh, S.S. Al-Deyab, M.H. El-Newehy, Fabrication of electrospun poly(vinyl alcohol)/dextran nanofibers via emulsion process as drug delivery system: Kinetics and in vitro release study, International Journal of Biological Macromolecules, 116 (2018) 1250-1259.

[20] S.S. Abolmaali, A.M. Tamaddon, R. Dinarvand, A review of therapeutic challenges and achievements of methotrexate delivery systems for treatment of cancer and rheumatoid arthritis, Cancer Chemotherapy and Pharmacology, 71 (2013) 1115-1130.

[21] E. Bernabeu, L. González, M. Cagel, M. Moretton, D. Chiappetta, Deoxycholate-TPGS mixed nanomicelles for encapsulation of methotrexate with enhanced in vitro cytotoxicity on breast cancer cell lines, Journal of Drug Delivery Science and Technology, 50 (2019).

[22] F. Zhang, J.-G. Zhang, J. Qu, Q. Zhang, C. Prasad, Z.-J. Wei, Assessment of anticancerous potential of 6-gingerol (Tongling White Ginger) and its synergy with drugs on human cervical adenocarcinoma cells, Food and Chemical Toxicology, 109 (2017) 910-922.

[23] S. Shen, L. Zhu, Z. Wu, G. Wang, Z. Ahmad, M. Chang, Production of triterpenoid compounds from Ganoderma lucidum spore powder using ultrasound-assisted extraction, Preparative Biochemistry \& Biotechnology, (2019) 1-14.

[24] L. Wang, Z. Ahmad, J. Huang, J.S. Li, M.W. Chang, Multi-compartment centrifugal electrospinning based composite fibers, Chemical Engineering Journal, 330 (2017).

[25] Z. Yao, L. Jin, Z. Ahmad, J. Huang, M. Chang, J. Li, Ganoderma lucidum polysaccharide loaded sodium alginate micro-particles prepared via electrospraying in controlled deposition environments, International Journal of Pharmaceutics, 524 (2017) 148-158.

[26] N. Bhardwaj, S.C. Kundu, Electrospinning: A fascinating fiber fabrication technique, Biotechnology Advances, 28 (2010) 325-347.

[27] P.P. Chu, M.J. Reddy, J. Tsai, Structural and transport characteristics of polyethylene oxide/phenolic resin blend solid polymer electrolytes, Journal of Polymer Science Part B: Polymer Physics, 42 (2004) 3866-3875.

[28] S.U. Patil, S.S. Yawale, S.P. Yawale, Conductivity study of PEO-LiClO4 polymer electrolyte doped with $\mathrm{ZnO}$ nanocomposite ceramic filler, Bulletin of Materials Science, 37 (2014) 1403-1409.

[29] S.B. Aziz, R.B. Marif, M.A. Brza, A.N. Hassan, H.A. Ahmad, Y.A. Faidhalla, M.F.Z. Kadir, Structural, thermal, morphological and optical properties of PEO filled with biosynthesized Ag nanoparticles: New insights to band gap study, Results in Physics, 13 (2019) 102220.

[30] A. Rezaei, M.R. Mohammadi, In vitro study of hydroxyapatite/polycaprolactone (HA/PCL) nanocomposite synthesized by an in situ sol-gel process, Materials Science and Engineering: C, 33 (2013) 390-396.

[31] M. Chakraborty, S. Dasgupta, C. Soundrapandian, J. Chakraborty, S. Ghosh, M.K. Mitra, D. Basu, Methotrexate intercalated ZnAl-layered double hydroxide, Journal of Solid State Chemistry, 184 (2011) 2439-2445. 
[32] K.J.a. Muhammad, S. Jamil, N. Basar, S.D. Sarker, M.G. Mohammed, Globrauneine A-F: six new triterpenoid esters from the leaves of Globimetula braunii, Natural Product Research, (2019) 1-8.

[33] C. Shen, L. Dai, B. Shen, X. Zhou, J. Bai, H. Xu, Q. Lv, J. Han, H. Yuan, Nanostructured lipid carrier based topical gel of Ganoderma triterpenoids for frostbite treatment, Chinese Journal of Natural Medicines, 13 (2015) 454-460.

[34] L. Zhang, T. Su, B. He, Z. Gu, Self-assembly polyrotaxanes nanoparticles as carriers for anticancer drug methotrexate delivery, Nano-Micro Letters, 6 (2014) 108-115.

[35] M. Pakravan, M.-C. Heuzey, A. Ajji, Core-shell structured PEO-chitosan nanofibers by coaxial electrospinning, Biomacromolecules, 13 (2012) 412-421.

[36] M. Sattary, M.T. Khorasani, M. Rafienia, H.S. Rozve, Incorporation of nanohydroxyapatite and vitamin D3 into electrospun PCL/Gelatin scaffolds: The influence on the physical and chemical properties and cell behavior for bone tissue engineering, Polymers for Advanced Technologies, 29 (2018) 451-462.

[37] J. Cielecka-Piontek, J. Dzitko, A. Talaczynska, Benefits and limitations of polymorphic and amorphous forms of active pharmaceutical ingredients, Current Pharmaceutical Design, 22 (2016).

[38] M.A. Dehcheshmeh, M. Fathi, Production of core-shell nanofibers from zein and tragacanth for encapsulation of saffron extract, International Journal of Biological Macromolecules, 122 (2019) 272-279.

[39] X. Li, C. Zhang, S. Wu, X. Chen, J. Mai, M. Chang, Precision printing of customized cylindrical capsules with multifunctional layers for oral drug delivery, ACS Applied Materials \& Interfaces, 11 (2019) 39179-39191.

[40] C. Atallah, S. Mortazavi, A.Y. Tremblay, Thermal stability of hydrophilic PEO-silane modified ceramic membranes, Colloids and Surfaces A: Physicochemical and Engineering Aspects, 561 (2019) 254-266.

[41] S.A. Popov, O.P. Sheremet, L.M. Kornaukhova, A.E. Grazhdannikov, E.E. Shults, An approach to effective green extraction of triterpenoids from outer birch bark using ethyl acetate with extractant recycle, Industrial Crops \& Products, 102 (2017) 122-132.

[42] M.J. Park, R.R. Gonzales, A. Abdel-Wahab, S. Phuntsho, H.K. Shon, Hydrophilic polyvinyl alcohol coating on hydrophobic electrospun nanofiber membrane for high performance thin film composite forward osmosis membrane, Desalination, 426 (2018) 50-59.

[43] K. Moomand, L.-T. Lim, Oxidative stability of encapsulated fish oil in electrospun zein fibres, Food Research International, 62 (2014) 523-532.

[44] L. Peng, L. Lingxue, H. Sheng, Z. Yonghong, X. Jianhua, Z. Zhiqiang, Anti-cancer effects of a neutral triterpene fraction from Ganoderma lucidum and its active constituents on SW620 human colorectal cancer cells, Anti-Cancer Agents in Medicinal Chemistry, 19 (2019) 1-8.

[45] H.S. Zhu, X.L. Yang, L.B. Wang, D.X. Zhao, L. Chen, Effects of extracts from sporoderm-broken spores of Ganoderma lucidum on HeLa cells, Cell Biology and Toxicology, 16 (2000) 201-206.

[46] L.M. Harhaji Trajković, S.A. Mijatović, D.D. Maksimović-Ivanić, I.D. Stojanović, M.B. Momčilović, S.J. Tufegdžić, V.M. Maksimović, Ž.S. Marjanovi, S.D. StošićGrujičić, Anticancer properties of ganoderma lucidum methanol extracts In vitro and in vivo, Nutrition and Cancer, 61 (2009) 696-707. 